\title{
Problem solved (probably)
}

\author{
Research could progress as never before as scientists embrace the ever-growing possibilities for \\ collaboration via the web.
}

Do you remember your first visit to the World Wide Web? When Lynx and Mosaic were the web browsers of the day, and favourite sites to help you navigate the (relatively few) pages were Lycos and Altavista? Not so long ago, but it seems a world away.

In fact, it is now 20 years since Tim Berners-Lee submitted to his bosses at CERN a document entitled Information Management: A Proposal. He was hoping, as he wrote later, to persuade them that the development of a global 'hypertext' system would be in the lab's interest, as it prepared for its greatest scientific endeavour, the Large Hadron Collider. In the system Berners-Lee had in mind, the reader could jump through 'hyperlinks' from one piece of electronic text to another, and the resulting web (or 'mesh', as it was dubbed in the original document) of interlinked documents would safeguard the immense amount of information about CERN's accelerators and experiments that is produced by an ever-changing set of people.

His proposal was successful, and the World Wide Web was born. It has since had a fundamental impact on our working lives - on how we browse library content, how we buy textbooks, how we make arrangements for conference travel. But the way in which most physicists actually do research day to day seems less affected. This, however, is bound to change, predicts Michael Nielsen in his Commentary on page 238 of this issue, as information becomes less static and more active. There are already examples of this, such as the blogs through which some scientists share information and ideas that might be too incomplete for formal publication, but that might inspire others and, ideally, catalyse collaboration. But it can go much further.

A striking example of where online collaboration might lead is the Polymath1 project, an experiment in 'massively collaborative mathematics' initiated by Fields medallist Tim Gowers, of the University of Cambridge, UK. In late January and early February this year, Gowers made a number of posts on his blog (http://gowers.wordpress.com) in which he explained a specific mathematical problem, its background and the procedures by which he hoped it could be solved "by means of a large collaboration in which no single person has to work all that hard". In the weeks that followed, a lively discussion developed in the comment section of the blog, with more than a dozen people making substantial scientific contributions; Nielsen set up a wiki to collate the insights gained and related material (http://michaelnielsen. org/polymath1). On 10 March 2009, Gowers announced: "Problem solved (probably)".

In a later post, Gowers wrote that for him "this has been one of the most exciting six weeks of my mathematical life". There were false starts and dead ends, but eventually, he says, the mathematicians proved collectively a stronger result than had initially seemed feasible. The full account of the project, and how it is documented, should serve as a valuable and lasting resource for a broad audience, and in particular for students: they will be able to trace, step by step, how great minds approach a problem, and see that the route to its solution is anything but linear.

Another approach to the sharing of scientific insight and discovery is that pursued by the proponents of 'open notebook science, in which the entire primary record of an ongoing research project is made openly available online. The movement started in corners of the chemistry community, but has now also reached physics. In January this year, for example, Tobias Osborne - a theoretical physicist at Royal Holloway, University of London - started to post his research notes online (http://tjoresearchnotes. wordpress.com). The information is there for everyone to see and comment on, plus Osborne is experimenting with features such as a 'reading group' (where he presents his thoughts about papers) and guest posts. For a faster fix, you could even try 'micro-blogging': websites such as Twitter. com let you share what's on your mind, 140 characters at a time, with a wide audience, including a growing community of (mostly) young researchers and science writers and journalists.

Legend has it that when Tim Berners-Lee's supervisor at CERN, Mike Sendall, read the now-famous proposal, he commented that it was "vague, but exciting". Online tools for research are developing rapidly, and even if the possibilities for changing the way we do science are vague as yet, they certainly are exciting.

\section{Science on hold}

\section{It was all going so well - but then Obama's science appointments were blocked.}

Following the election of Barack Obama as US President in November 2008, an impressive line-up of scientists was nominated to join the new administration and a financial stimulus package passed that will pump billions of dollars into US science.

But last month two key nominations - of John Holdren as Assistant to the President for Science and Technology, and Jane Lubchenco as head of the National Oceanic and
Atmospheric Administration - were 'on hold'. US Senators each enjoy the right to put a hold, anonymously, on any nomination if they so wish, and someone did so in the cases of Holdren and Lubchenco for, it seems, leverage on issues unrelated to science.

It's a frustratingly undemocratic part of the political process, especially so in the face of pressing need for movement on scientific issues and for Holdren's and Lubchenco's expertise in their respective roles. Delight among scientists and scientific organizations at the prompt nomination by Obama of a presidential science adviser was soured by the delay. Fortunately, following intense lobbying, the nominations are now confirmed.

As the Obama administration finally takes shape, the system of holds - along with that of earmarking - surely deserves the attention of lawmakers. 